\title{
"La diferencia es que ellas son desplazadas y yo soy víctima": desplazamiento interno y agenda posconflicto en el Perú*
}

\section{"The Difference is that They are Displaced and I Am a Victim": Internal Displacement and Post- Conflict Agenda in Peru}

Iván Ramírez Zapata ${ }^{* *}$

Recibido: 27 de septiembre 2016

Aprobado: 5 diciembre de 2016

Disponible en línea: 30 de enero de 2017

\section{Resumen}

El Perú vivió un conflicto armado interno entre 1980 y 2000. Se calcula que esta etapa produjo alrededor de seiscientos mil desplazamientos internos; sin embargo, es también un tema relegado en el conjunto de prioridades de la agenda posconflicto peruana. Este artículo ofrece una explicación para tal paradoja. Se identifican seis factores que explican el relegamiento del desplazamiento en la agenda posconflicto: 1) menores probabilidades de identificarse con la afectación de desplazamiento que con afectaciones caracterizadas por ataques directos contra la integridad física; 2) un marco de sentido en el cual la idea de "víctima” (del conflicto armado) no incluye la figura del desplazado; 3) la naturaleza del concepto de desplazamiento, cuyos elementos definitorios destacan el contexto

\section{Abstract}

Peru experienced an internal armed conflict between 1980 and 2000. It is estimated that this stage produced around six-hundred thousand internal displacements; however, it is also a relegated issue in the set of priorities of the Peruvian post-conflict agenda. This article offers an explanation for this paradox. I identify six factors that relegate displacement in the post-conflict agenda: 1) lower probabilities for subjects to identify with displacement than with damages characterized by direct attacks on physical integrity; 2) a framework of meaning in which the idea of "victim" (of the armed conflict) does not include the figure of displaced person; 3 ) the nature of the concept of displacement, whose defining elements highlight the context in which it occurs, rather than relating an aggressor to a

doi:10.11144/Javeriana.papo22-1.ddvd

* Artículo de revisión

** Bachiller en Antropología por la Universidad Nacional Mayor de San Marcos. Correo electrónico: ivan.ramirez. zapata@gmail.com. Agradezco al sociólogo Félix Reátegui, quien leyó una versión previa de este artículo y realizó comentarios pertinentes. Orcid: http://orcid.org/0000-0002-5426-3303 
en el que este ocurre antes que relacionar a un agresor con una víctima; 4) la necesidad de un discurso experto sobre el desplazamiento como condición para activar procesos de identificación con esta categoría; 5) la historia de movilidad interregional previa al desplazamiento, que resta especificidad a esta experiencia; y 6) el tratamiento que hace la Comisión de la Verdad y Reconciliación (CVR) sobre el desplazamiento. Esta argumentación ofrece dos aportes: 1) iniciar una discusión sobre la manera en que distintas afectaciones se relacionan y 2) mostrar límites de la agenda posconflicto poco explorados en la academia peruana.

\section{Palabras clave:}

Perú; desplazamiento interno; posconflicto; Comisión de la Verdad y Reconciliación; víctimas

\footnotetext{
Cómo citar este artículo:

Ramírez Zapata, I. (2017). "La diferencia es que ellas son desplazadas y yo soy víctima": desplazamiento interno y agenda posconflicto en el Perú. Papel Político, 22(1), 127-157. https:// doi.org/10.11144/Javeriana.papo22-1.ddvd
}

victim; 4) the need for an expert discourse on displacement as a condition to activate processes of identification with this category; 5) the history of interregional mobility prior to displacement, which diminishes specificity to this experience; and 6) the treatment made by the Peruvian Truth and Reconciliation Commission (TRC) on displacement. This argument makes two contributions: a) it starts a discussion about the way in which different affections are related, and b) shows limits of the post-conflict agenda that have been little explored in the Peruvian academy.

\section{Keywords:}

Peru; internal displacement; post-conflict; Truth and Reconciliation Commission; victims 


\section{Introducción}

El Perú vivió un periodo de violencia armada en el último tramo del siglo XX. La Comisión de la Verdad y Reconciliación (CVR ${ }^{1}$ caracterizó este periodo como uno de "conflicto armado interno", y estimó que este tuvo lugar entre 1980 y 2000. Asimismo, proyectó una cifra de 69280 víctimas mortales como resultado de ese proceso (CVR, 2003), además de ratificar el cálculo, ya conocido por ese entonces entre las organizaciones de la sociedad civil involucradas en trabajar con poblaciones que sufrían los embates de la violencia, de más de medio millón de personas desplazadas (Mendoza, 2012).

El desplazamiento interno rara vez ha sido parte de las preocupaciones centrales de los académicos que investigan temas de conflicto armado y posconflicto en el Perú. El estado de la cuestión que hiciera Carlos Iván Degregori (2011), quien fuera el principal estudioso peruano de este periodo, muestra que aspectos como las causas del inicio de conflicto armado, el surgimiento y la derrota del grupo subversivo Sendero Luminoso, el rol de las mujeres dentro de esta organización, la estrategia contrasubversiva estatal, la relación de las universidades con los hechos de este periodo, la acción subversiva en la selva y sus consecuencias sobre comunidades amazónicas y la desarticulación de las relaciones sociales en el ámbito rural son los temas a los cuales mayor interés se les ha dado desde la investigación y reflexión académica. En este balance, no hay mención alguna a publicaciones sobre desplazamiento interno. Asimismo, dos revisiones bibliográficas recientes alrededor de esta etapa se centran en la nueva producción historiográfica, con énfasis en los retos para el uso de fuentes, la importancia de la historia regional y las trayectorias políticas detrás del desarrollo de organizaciones subversivas (Ragas, 2013; Rénique, 2015), mencionándose solo una investigación (no publicada) sobre desplazamiento. ${ }^{2}$ Un cuarto balance (Salazar Borja, 2015) revisa investigaciones desde el punto de vista de los estudios sobre memoria e incluye tres referencias a textos sobre desplazados; de estas, el autor reseña solo una, pero sin mencionar que esa investigación se hizo con población que experimentó desplazamiento interno y que años después regresó a la comunidad en la que vivía antes del conflicto. ${ }^{3}$

También es poco lo que la academia peruana ha hecho sobre comparación con otras experiencias latinoamericanas de conflictos internos. Algunos textos, que parten de una preocupación por las violaciones de los derechos humanos y la defensa de estos, han comparado las experiencias de la Asociación Nacional de Familiares de Secuestrados, Detenidos y Desaparecidos del Perú (Anfasep) con las Madres de la Plaza de Mayo de Argentina, en cuanto ambas constituyen experiencias destacadas de organizaciones civiles conformadas por familiares de quienes sufrieron violaciones a sus derechos humanos

\footnotetext{
${ }^{1}$ La CVR se creó en junio de 2001 y entregó su Informe final el 28 de agosto de 2003.

2 Dicho trabajo es la tesis de maestría de Aroni Sulca (2013).

${ }^{3}$ El trabajo reseñado es Del Pino (2003).
} 
(Muñoz, 1999; Tamayo, 2003). Partiendo de la misma preocupación, otros autores han comparado las prácticas de tortura y abuso llevados a cabo por efectivos militares, ya sea en bases contrainsurgentes, en el caso peruano, ya sea en edificios estatales o clandestinos, para el caso de dictaduras militares latinoamericanas (Degregori, Portugal, Salazar y Aroni, 2015; Youngers, 2003). Sin embargo, con la sola excepción de una publicación de hace dos décadas (IDL, 1997), la academia peruana no ha hecho paralelos entre el Perú y Colombia, que son los dos únicos países en Suramérica que han sufrido desplazamientos masivos a causa de conflictos armados internos. Más aún, mientras en Colombia el desplazamiento interno es un elemento que ha estado incorporado en la agenda pública (Rodríguez Garavito y Rodríguez Franco, 2010), en el Perú no tiene la misma relevancia.

Si bien puede parecer mezquino cuantificar el dolor cuando hablamos de violaciones de derechos humanos, es cierto que establecer cifras permite contar con referencias que den cuenta de la magnitud de los daños y abusos ocasionados; si no fuese así, no sería tan común en el Perú hacer mención de las casi setenta mil víctimas mortales que dejó la espiral de violencia, ni se haría énfasis en las aproximadamente quince mil personas desaparecidas y ejecutadas extrajudicialmente en este periodo. ¿̇Por qué, sin embargo, los cientos de miles de personas que quedaron en situación de desplazamiento interno son pocas veces referidas en los recuentos numéricos de la violencia?

En una de las pocas miradas sobre desplazamiento interno, Barrantes (2012) llama la atención sobre el hecho de que, incluso, la propia CVR no abordó a fondo este tema, y señala como hipótesis que esto se debería a que esta comisión puso énfasis en documentar casos de tortura, desaparición forzada, masacres y ejecuciones extrajudiciales, es decir, aquellos delitos que mejor se adecuaban a la mirada sobre violaciones a los derechos humanos prevalecientes en las organizaciones civiles peruanas involucradas en su defensa, cuya preocupación se centró en los ataques directos contra la vida y la libertad y en la identificación de los agentes que los perpetraron.

Tenemos, pues, una paradoja. A la par que el desplazamiento interno fue el fenómeno numéricamente más relevante del conflicto interno, es también uno de los menos atendidos por la academia. Después de terminado el conflicto, el desplazamiento tampoco ha recibido demasiado interés político en comparación con otro tipo de daños y abusos. Es a este hecho que se aproxima el presente artículo. Argumento que el desplazamiento es un tema relegado a un segundo plano en la agenda posconflicto peruana, debido a seis factores: 1) menores probabilidades de identificarse con la afectación de desplazamiento que con afectaciones caracterizadas por ataques directos contra la integridad física; 2) la configuración de un marco de sentido en el cual la idea de "víctima" (del conflicto armado) no incluye la figura del desplazado; 3) la naturaleza misma del concepto de desplazamiento, cuyos elementos definitorios destacan el contexto en el que ocurre la migración 
antes que la relación entre un agresor y su víctima; 4) la necesidad de un discurso experto sobre el desplazamiento como condición para activar procesos de identificación con esta afectación; 5) la historia de movilidad interregional previa al desplazamiento que resta especificidad a esta experiencia; y 6) el tratamiento que hace la CVR sobre el desplazamiento y el lugar que les asigna a los desplazados en su propuesta de reparación.

El siguiente segmento de este artículo presenta el enfoque que adopto en el tratamiento del desplazamiento. El tercero repasa rápidamente las principales características del desplazamiento dentro del conflicto armado interno peruano. La cuarta sección describe el contenido de la agenda posconflicto peruana. Los apartados del quinto al décimo analizan elementos problemáticos referidos a la definición del desplazamiento y la identificación de las personas objetivamente desplazadas con esta categoría. Finalizo con las conclusiones.

\section{El enfoque}

El concepto desplazamiento interno hace referencia a las personas o grupos de personas que se han visto forzadas u obligadas a escapar o huir de su hogar de residencia habitual, en particular como resultado o para evitar los efectos de un conflicto armado, situaciones de violencia generalizada, de violaciones de los derechos humanos o de catástrofes naturales o provocadas por el ser humano, y que no han cruzado una frontera estatal internacionalmente reconocida (Oficina de Coordinación de Asuntos Humanitarios de las Naciones Unidas, 2010, p. 12).

En este concepto, de orden jurídico-normativo, son dos los elementos esenciales que definen el desplazamiento: 1) la migración a consecuencia de una amenaza a la seguridad y 2) el hecho de que la persona que migra no ha traspasado una frontera internacional. Varios autores han destacado estos mismos elementos en el momento de definir el desplazamiento para el caso peruano sin ofrecer mayor reparo (Coronel, 1999; Diez Hurtado, 2003; Gibaja Vargas-Prada, 1994; Kirk, 1991); asimismo, han subrayado un elemento importante: el desplazamiento como estrategia para salvar la vida de uno mismo y de la familia. Siguiendo esta observación, evito hablar de desplazamiento "forzado": al describir el desplazamiento como una estrategia, se está haciendo énfasis en el hecho de que se trata de una decisión. Es decir, una persona o familia puede decidir desplazarse o no. ${ }^{4}$ Sin embargo, más allá de este señalamiento, no existen textos que discutan el desplazamiento interno como experiencia, es decir que se aproximen con detenimiento a los sentidos y las narrativas que las mismas personas desplazadas han elaborado al respecto. En ese sentido, mi acercamiento privilegia una aproximación cualitativa, que

\footnotetext{
${ }^{4}$ Más aún, la misma comunidad de la que es miembro un desplazado puede ser consciente de que se trata de una decisión, y tener sentimientos encontrados al respecto. Por ejemplo, un estudio en un distrito de la sierra peruana halló una polarización social y política entre quienes se desplazaron y quienes se quedaron en la comunidad durante todo el periodo de conflicto. Estos reprochaban a aquellos su "cobardía" y el "abandono" del pueblo, tensiones que aparecieron incluso en las dinámicas electorales municipales de 1995 (Tinoco y Cáceres, 1999, p. 54).
} 
busca dar cuenta de las asociaciones entre el desplazamiento como experiencia y el escenario posconflicto más amplio.

Asimismo, contrasto el acercamiento al desplazamiento como experiencia con la conceptualización normativa para mostrar cómo interactúan en la producción de subjetividades y, a su vez, para destacar una característica conceptual importante: el desplazamiento es una afectación cuya definición está centrada en el contexto en el que ocurre, mientras que otras afectaciones se definen sobre la base de una acción cometida. El término afectaciones se refiere a los distintos tipos de daño y perjuicio cometidos contra la población durante el conflicto armado. Mostraré que la distancia que hay entre normativa y experiencia sobre desplazamiento es un elemento que relega esta afectación a un segundo plano de la agenda posconflicto en comparación con otras, tales como desaparición, tortura o violación sexual.

Las discusiones que propongo aquí se nutren de la información recogida en una investigación más amplia -no publicada - sobre el desplazamiento interno en el escenario posconflicto peruano, realizada entre 2012 y 2016 en Lima. Se llevaron a cabo veinte entrevistas a personas desplazadas residentes en el distrito de Ate y Lurigancho-Chosica (ninguno de los entrevistados intentó en algún momento retornar a sus comunidades de origen). ${ }^{5}$ Se entrevistó también a diez personas que desde organizaciones no gubernamentales trabajaron en uno o varios momentos con población desplazada, siete entrevistas a funcionarios y exfuncionarios de instituciones estatales encargadas de trabajar con desplazados, y dos entrevistas a personas que han visto el tema tanto desde organizaciones no gubernamentales como desde instancias estatales. Asimismo, en este tiempo, colaboré en dos proyectos de organizaciones no gubernamentales, organizando tres grupos focales con desplazados en Lima y acompañando cuatro reuniones de base de desplazados en las regiones de Junín, Loreto, Ica y Ayacucho. También en este tiempo participé durante un año y medio del equipo que implementó el Lugar de la Memoria, la Tolerancia e Inclusión Social, ${ }^{6}$ lo cual supuso asistir a reuniones y sostener conversaciones con grupos de víctimas, activistas y funcionarios estatales ligados al tratamiento de las consecuencias del conflicto armado. Las ideas aquí expuestas se alimentan también de observaciones y reflexiones suscitadas dentro de estas labores.

Con este artículo, pretendo dar pie a dos discusiones que no han aparecido en la producción bibliográfica existente sobre desplazamiento, conflicto armado y posconflicto en el Perú. La primera es qué pasa con el desplazamiento interno luego de acabado el

\footnotetext{
${ }^{5}$ Autores como Diez Hurtado (2003), Mendoza Mesías (2012) y Condecorep (2004) afirman que la mayoría de los desplazados optaron por no volver a sus comunidades e iniciaron una nueva vida en las ciudades en que se instalaron. ${ }^{6}$ El Lugar de la Memoria, la Tolerancia e Inclusión Social alberga una muestra museográfica permanente sobre el conflicto armado peruano. Se encuentra ubicado en el distrito limeño de Miraflores y su inauguración tuvo lugar en diciembre de 2015.
} 
conflicto armado y cómo esta problemática se relaciona con las otras formas de afectación presentes en el escenario posconflicto. La segunda es cómo el desplazamiento expresa algunos de los límites de la agenda posconflicto peruana.

\section{Desplazamiento interno por conflicto armado en el Perú}

El conflicto armado interno peruano tuvo como sus principales protagonistas armados a las organizaciones subversivas Sendero Luminoso y Movimiento Revolucionario Túpac Amaru, a las Fuerzas Armadas y Policiales y a las unidades campesinas y amazónicas de autodefensa (CVR, 2003). Además de las casi setenta mil víctimas mortales y medio millón de desplazados, la CVR calculó que esta experiencia dejó cuarenta mil niños huérfanos y más de veinte mil mujeres viudas. La violencia armada afectó sobre todo las zonas rurales y pobres del país. Así, el departamento serrano de Ayacucho concentró más de 40 \% de las víctimas mortales reportadas a la CVR. Asimismo, 79 \% de las víctimas reportadas vivía en zonas rurales y 56 \% estaba ocupada en actividades agropecuarias (CVR, 2003, t. 8, p. 245). Estos datos permitieron establecer el perfil arquetípico de una víctima (o afectado) de este periodo: "pobres, rurales, indígenas, habitantes de lugar distantes de Lima" (Degregori, 2015, p. 44).

Es difícil establecer el grado de confiabilidad de las cifras que existen sobre desplazamiento interno. Este no es un problema específico del Perú: en el ámbito internacional se reconoce que el conteo de este tipo de población presenta inconvenientes que aún no se han resuelto, tales como la poca difusión de la existencia de iniciativas dirigidas a censar a quienes han sido desplazados, el miedo a identificarse como tal por temor a represalias o estigmas, la existencia de situaciones donde es difícil distinguir entre un desplazado y alguien que migró buscando mejores oportunidades, entre otras (United Nations, Economic and Social Council. E /CN.3/2016/14). Hecha esta salvedad, pueden señalarse algunos números al respecto. Los estudios hechos por el Estado peruano a inicios de la primera década del siglo XXI (Coral, 2002) señalaban que los desplazados residían temporalmente en varios lugares, entre dos y cinco, antes de la definición de su lugar de residencia definitiva; asimismo, encontraron que $56 \%$ de la población desplazada volvió a las comunidades en las que vivía antes de salir y que entre 25 y 30 \% se movilizó hacia Lima.

Una fuente distinta, centrada exclusivamente en desplazados que vivían en ciudades, señala que, en las regiones de Ayacucho, Junín, Huancavelica, Apurímac, Ucayali, ocurrieron la mayor cantidad de desplazamientos; del total de personas que se habrían trasladado desde espacios rurales hacia distintas ciudades del país, la mayor parte se habría dirigido a Ayacucho (34.2 \%), Huánuco (13.6 \%), Junín (11.3 \%) y Lima (16.3 \%) (Mimdes, 2010).

Más allá de cualquier discusión sobre el carácter de estas cifras, queda clara la masividad del fenómeno. Asimismo, es ampliamente reconocido que quienes pasan por experiencias de desplazamiento ven restringido el goce efectivo de sus derechos (Leckie, 
2007; Oficina de Coordinación de Asuntos Humanitarios de las Naciones Unidas, 2010; IASC, 2010), a la vez que se encuentran especialmente vulnerables ante la pobreza (Distr. GENERAL E/CN.4/1998/53/Add.2; Misión ICVA, 1997; UNHCR, 2004) y presentan deterioros en su salud y menores niveles de logro educativo (Akresh y De Walque, 2008; Bundervoet, Verwimp y Akresh, 2009; Grimard y Laszlo, 2014; León, 2012; Moya, 2010).

Gracias a la insistencia de la comunidad internacional, y en especial después de que Francis M. Deng, entonces representante del Secretario General de las Naciones Unidas sobre los Derechos Humanos de los Desplazados Internos, se reuniese con el presidente Alberto Fujimori, el Perú asumió la responsabilidad de afrontar el problema del desplazamiento interno. Por ello, en 1993, se creó el Programa de Apoyo al Repoblamiento y Desarrollo de Zonas de Emergencia, que constituyó durante diez años la única política estatal específica sobre desplazamiento; esta tuvo como misión establecer condiciones básicas para el desarrollo humano y sostenible en las zonas declaradas en estado de emergencia, de forma que así se luchara por reestablecer la pazy erradicar la pobreza (Francke, Castro, Francke y Espino, 2001). Este programa pasó por diversas etapas hasta que en 2004 desapareció y fue reemplazado por la actual Dirección de Desplazados y Cultura de Paz, perteneciente al Ministerio de la Mujer y Poblaciones Vulnerables (MIMP).

$\mathrm{Al}$ 2017, hay dos leyes especialmente relevantes para la población desplazada por el conflicto interno (Mimdes, 2010). La primera, emitida en 2004, es la Ley 28223, Ley sobre los Desplazamientos Internos, que tiene por objeto reconocer la naturaleza legal del estatuto específico de "desplazado" y definir sus derechos y garantías durante los distintos momentos del desplazamiento. Según esta ley, el MIMP es el ente rector encargado de los desplazados en el Perú, tarea que hoy ejerce a través de la referida dirección.

En 2005, apareció una segunda ley relevante para la población internamente desplazada específicamente por conflicto armado. Se trata de la Ley 28592, que crea el Plan Integral de Reparaciones. De acuerdo con el reglamento de esta ley, emitido en 2006, el objetivo de la reparación es

permitir su acceso [de las personas afectadas] a la justicia, la restitución de sus derechos, la resolución de las secuelas derivadas de las violaciones a los derechos humanos y la reparación material y moral, específica o simbólica, por los daños sufridos [para lograr el] restablecimiento y plena vigencia de los derechos así como de las condiciones, recursos, capacidades, oportunidades y calidad de vida perdidos por efecto del proceso de violencia y sus secuelas. (Mimdes, 2010, p. 77)

Según la normativa del Plan Integral de Reparaciones, el desplazamiento interno califica como una afectación derivada del conflicto, por lo cual tienen el derecho a reclamar reparaciones quienes pueden demostrar haber pasado por esta experiencia. Debe 
notarse, sin embargo, que dentro de esta normativa se considera desplazado aquel que no ha retornado a las comunidades en que residía antes de iniciarse el conflicto. Como se verá más adelante, tanto la CVR como los programas de reparación hacen referencia a desplazados "no retornantes" en el momento de hablar de esta afectación.

Ambas leyes han dado pie a un marco institucional de atención a los afectados por el conflicto, donde están incluidos los desplazados. Sin embargo, la afectación del desplazamiento está lejos de tener un lugar protagónico en la agenda más amplia de retos y deudas derivados del conflicto interno. En el siguiente apartado, describo el contenido de esta agenda.

\section{¿Cuál es la agenda posconflicto en el Perú?}

No es fácil responder la pregunta. Primero, porque ningún tipo de liderazgo reconocible o autoridad estatal de primer orden ha hecho referencia alguna vez a la existencia de una agenda de este tipo, con sus respectivas prioridades y enfoques. En segundo lugar, porque los actores interesados tienen lógicas y prioridades distintas, derivadas de su diferente naturaleza, por lo cual sus coincidencias respecto de los temas por tratar y la manera en que deben ser tratados son parciales.

Los principales actores involucrados en la atención a las consecuencias y secuelas del conflicto armado son estas: 1) las organizaciones de afectados, que demandan reparaciones dignas, una judicialización eficaz a los casos de violaciones de derechos humanos y la búsqueda de sus familiares desaparecidos; 2) las organizaciones no gubernamentales agrupadas alrededor de la Coordinadora Nacional de Derechos Humanos, que dan apoyo y asesoría a personas afectadas en función de su disponibilidad de recursos humanos y monetarios; 3) la Defensoría del Pueblo, que publica informes de seguimiento sobre las deudas pendientes del Estado para con la población afectada; 4) diversas oficinas estatales, principalmente las encargadas de implementar la ley Plan Integral de Reparaciones y la ley de desplazados, así como el Lugar de la Memoria, la Tolerancia e Inclusión Social; 5) intelectuales y académicos, resaltando aquellos que forman parte del Instituto de Democracia y Derechos Humanos de la Pontificia Universidad Católica del Perú, creado después de que la CVR culminase su trabajo; y 6) grupos civiles de activistas. La agenda posconflicto es aquel conjunto de temas prioritarios por tratar surgido de las interacciones entre estos actores, sus acuerdos y disputas, y que están presentes en sus publicaciones y declaraciones. Asimismo, es importante señalar que esta agenda se alimenta del conjunto de recomendaciones que la CVR estimó necesarias para consolidar el proceso de reconstrucción de la democracia en el país, y que consignó en el tomo 9 de su Informe final (CVR, 2003).

Considero que son cinco grandes temas los que componen la agenda posconflicto peruana. Tres de ellos son los que recurrentemente forman parte de los sucesivos informes que sobre el nivel de avance de la acción estatal en la atención a los daños 
derivados del conflicto hace la Defensoría del Pueblo (2006, 2008, 2013), a saber, la ejecución de reparaciones, la judicialización de violaciones a los derechos humanos y la búsqueda de personas desaparecidas.

Se trata, asimismo, de temas que desde hace alrededor de una década el Estado peruano ha incorporado a su mandato legal: la política de reparaciones surge con la ley Plan Integral de Reparaciones en 2005; en 2004, se promulga la Ley 28413, "Ley que regula la ausencia por desaparición forzada durante el periodo 1980-2000", que constituyó una primera iniciativa oficial sobre el tema; 7 mientras que la judicialización de violaciones a los derechos humanos ha sido la principal línea de trabajo del movimiento de derechos humanos desde las épocas del conflicto, además de ser tema de constantes llamados de atención de la Corte Interamericana de Derechos Humanos al Perú desde mediados de la década de 1990 (Burt y Rodríguez, 2014). Por lo demás, la primera sentencia en una corte nacional por violaciones a los derechos humanos tuvo lugar en 2006 con una sentencia condenatoria a cuatro policías por la desaparición del estudiante Ernesto Castillo Páez en octubre de 1990.

Un cuarto tema es el de la enseñanza en la escuela sobre el conflicto armado. Si bien esta no es una demanda específica de individuos y organizaciones de afectados, aparece cada cierto tiempo en los medios de comunicación alguna polémica sobre los contenidos de esta enseñanza (De Belaúnde, 2012; Uccelli et al., 2013).

El filósofo Salomón Lerner, quien presidiera la CVR, y que ocupa la presidencia ejecutiva del Instituto de Democracia y Derechos Humanos de la Pontificia Universidad Católica del Perú, escribió un documento hace pocos años en el que da cuenta de lo que a su juicio es "la agenda de la verdad y la justicia" luego de nueve años de entregado el Informe final. En este texto, la agenda que Lerner (2012) postula tiene tres puntos: memoria, reparaciones y justicia. Los dos últimos coinciden con dos de los temas recurrentes en los informes de la Defensoría del Pueblo. "Memoria" puede considerarse el quinto tema de la agenda posconflicto y se refiere concretamente a las iniciativas de memorialización (museos, monumentos, placas, etc.) que han tenido lugar a propósito del conflicto interno. A este respecto, un primer hecho por destacar es que el informe escrito de la CVR fue acompañado de una muestra fotográfica (Yuyanapaq, hoy ubicada en un ambiente del Museo de la Nación ${ }^{8}$ ); una segunda constatación es la existencia de más de un centenar de experiencias de memorialización en el ámbito local (Reátegui, 2010); lo tercero por subrayar es que uno de los aspectos más debatidos del escenario posconflicto se relaciona

\footnotetext{
${ }^{7}$ En el momento de redactar este artículo, la principal demanda de las organizaciones de afectados y activistas es la implementación de la Ley 30470, Ley de Búsqueda de Personas Desaparecidas durante el Periodo de Violencia 1980-2000, emitida por el Estado peruano a mediados de 2016. La búsqueda de desaparecidos ha sido la principal demanda de la agenda posconflicto en los últimos años. Para una síntesis de los diversos aspectos alrededor de esta demanda, véase Colectivo Desvela (2015).

8 Ubicado en el mismo edificio de la sede central del Ministerio de Cultura, en el distrito de San Borja, en Lima.
} 
con un monumento ubicado en Jesús María (Drinot, 2009; Milton, 2015), distrito limeño de clase media. La memorialización es también un aspecto que el Estado ha asumido progresivamente, y que tiene un punto de inflexión en la implementación y apertura del Lugar de la Memoria, la Tolerancia e Inclusión Social, siendo junto con Yuyanapaq las dos experiencias de memorialización con auspicio oficial más importantes.

Mientras que los informes de la Defensoría se refieren a la temática de desplazamiento subsumida dentro de la preocupación por el avance de las reparaciones, el tema está totalmente ausente de la agenda que el texto de Salomón Lerner propone. Asimismo, es difícil ligar el tema de desplazamiento con la demanda de justicia, en cuanto en el Perú no hay experiencias de judicialización de casos de desplazamiento por el conflicto armado, ni ha sido una posibilidad contemplada por las organizaciones de derechos humanos. ${ }^{9}$ Esto último ha abonado a que la relación entre el desplazamiento interno y los organismos civiles de defensa de derechos humanos sea distante; una exsecretaria de la Coordinadora Nacional de Derechos Humanos sostiene que "quizás la relación entre grupo de derechos humanos y los desplazados es más esporádica, fría y lejana porque los desplazados no necesariamente judicializan", ${ }^{10}$ es decir, no pueden ser integrados a la estrategia de identificar responsables de crímenes, que ha sido una de las ramas históricas de trabajo de las instituciones de derechos humanos. En efecto, se ha sostenido que el foco de atención de estas instituciones ha estado puesto "en cuestionar las leyes de amnistía, en proseguir con los casos en los tribunales y otros asuntos similares” (Youngers, 2003, p. 440).

Desconectado de la lucha por la judicialización, distantes de los grupos de derechos humanos de la sociedad civil, y considerados como un subcapítulo en las demandas por reparaciones, los desplazados tienen una articulación poco favorable con la agenda posconflicto peruana. Los siguientes apartados abordan analíticamente los elementos que dan forma a esta situación, poniendo énfasis en las narrativas y el sentido que las personas desplazadas dan a esta experiencia.

\section{El desplazamiento entre las múltiples afectaciones del conflicto}

Cuando la CVR estimó que las víctimas mortales del conflicto serían alrededor de setenta mil y cuando, a su vez, ratificó que serían poco más de medio millón las personas desplazadas, lo que también estaba diciendo es que entre esos cientos de miles de desplazados se encontraban, no solo familiares directos e indirectos de las víctimas mortales, sino también un segmento grande de víctimas no mortales, contingentes conformados por

\footnotetext{
${ }^{9}$ Esto, a pesar que el Estado peruano ratificó los convenios internacionales 107 y 169 de la Organización Internacional del Trabajo, en 1960 y 1994, respectivamente, donde se reguló expresamente el derecho de los pueblos indígenas y tribales a no ser trasladados forzosamente de sus territorios salvo con ciertas excepciones. Sin embargo, recién a partir de la dación de la ley de desplazados en 2004, se reglamentó la prohibición de desplazamientos forzados.

${ }^{10}$ Entrevista con Rocío Silva Santisteban (16 de marzo de 2016).
} 
quienes pasaron experiencias de violencia sexual, tortura en una base militar y varios otros crímenes. En concreto, el Informe final señala:

La CVR ha recibido abundantes testimonios sobre desplazamiento producido como reacción directa a violaciones específicas de los derechos fundamentales, producidas por los agentes del conflicto armado, incluyendo asesinatos, tortura, tratos crueles, inhumanos o degradantes, violencia contra la mujer, secuestros, detenciones arbitrarias, expropiaciones y destrucción de bienes. (CVR, 2003, t. 6, p. 457)

En ese sentido, es esperable que un segmento enorme de quienes sufrieron algún tipo de daño o abuso durante el conflicto sean, entre otras cosas, desplazados. Así, las señoras que conforman la Asociación Nacional de Familiares de Secuestrados, Detenidos y Desaparecido del Perú (Anfasep) ${ }^{11}$-organización cuya sede principal se encuentra en Ayacucho- son desplazadas, si bien esta condición no aparece en la denominación de la organización, que resalta más bien el parentesco con quienes sufrieron detención, secuestro y desaparición. Lo mismo puede decirse de la Asociación Nacional de Familiares de Desaparecidos, Ejecutados Extrajudicialmente y Torturados (Anfadep), ubicada en el distrito de Lurigancho-Chosica, en Lima, ${ }^{12}$ cuya nomenclatura no resalta el hecho de tratarse de personas desplazadas; no obstante, lo son.

Las entrevistas que he realizado con personas desplazadas arrojan testimonios que van en el mismo sentido. Por ejemplo, un dirigente de desplazados en Puno sostiene que sus afectaciones son cuatro, pero que se reconoce, sobre todo, como desplazado. ${ }^{13}$ Una dirigente destacada en Lima que se reconoce desplazada, pero su principal lucha se relaciona con la desaparición de su padre a manos del Ejército y el intento de asesinato que sufrió su madre, siendo el desplazamiento la afectación con la que menos se identifica, o que es menos notoria en sus intervenciones públicas. ${ }^{14}$ En términos más amplios, mientras que una misma persona puede haber sido afectada por el conflicto de varias maneras, difícilmente se identifica con todas con la misma intensidad. Como muestra la mayoría de casos aquí señalados, identificarse principalmente como desplazado es menos probable cuando hay otras formas de identificación posibles que permiten acceder de forma más eficiente a los derechos de justicia, verdad y reparación.

\footnotetext{
${ }^{11}$ Fundada en 1982, Anfasep es una organización formada por familiares de personas que sufrieron violaciones a sus derechos humanos. El grueso de las mujeres que la conforman son personas quechuahablantes de origen rural. Para mayores detalles, véase Anfasep (2007).

${ }^{12}$ Anfadep se funda en mayo de 2003 a consecuencia de una negociación del Estado peruano con la Corte Interamericana de Derechos Humanos, donde aquel se compromete a dar atención y reparación específica a 159 casos. Los familiares involucrados en estos son los que la constituyen (Paz Ruiz, 2004, p. 21).

${ }^{13}$ Entrevista con Kevin Anzualdo (2 de febrero de 2016). Distrito de Lurigancho-Chosica (Lima). Por consideraciones éticas, la gran mayoría de nombres de las personas entrevistadas han sido cambiados.

${ }^{14}$ Entrevista con Cecilia Quispe (21 de abril de 2016). Distrito de Ate (Lima).
} 
Hay, no obstante, organizaciones cuyas principales demandas están vinculadas a la afectación derivada del desplazamiento interno y se encuentran afiliadas, o bien a la Coordinadora Nacional de Desplazados y Comunidades en Reconstrucción del Perú (Condecorep), o bien a la Coordinadora Nacional de Organizaciones de Víctimas y Afectados por la Violencia Política del Perú (Conavip). La primera fue fundada a mediados de la década de 1990, la segunda se fundó a inicios de la primera década del siglo XXI. Y mientras la primera tiene la identificación del desplazamiento en su denominación, la segunda persigue una representación general que abarque a todo aquel que haya sufrido algún daño durante el conflicto, independiente del tipo de afectación. Si bien podría pensarse que más eficiente para las demandas de atención y reparación sería la conformación de una sola organización, la existencia de dos grupos nacionales pone en cuestión la viabilidad de una unión de este tipo. Sean cuales sean las razones de esta división, lo cierto es que la relegación del desplazamiento respecto de otras afectaciones es una de las razones que un dirigente de Condecorep encuentra para explicar tal situación: "Conavip llama a sus marchas pero habla de la reparación económica, que es para viudas o los hijos de los muertos, no habla de desplazados". ${ }^{15}$

Las observaciones hechas hasta aquí permiten establecer dos cosas. Primero, que dentro de este universo de afectaciones, la identificación como desplazados se encuentra en segundo plano respecto de la identificación con otras formas de afectación, tanto en lo individual como en la intervención pública. Segundo, existe un universo de personas que se identifican principalmente como desplazadas. En un contexto en el cual el desplazamiento es una afectación relegada, es probable que sus demandas y sus problemas tengan un menor grado de visibilidad en actos públicos de rememoración y reivindicación de los afectados.

\section{El desplazado y la víctima}

De acuerdo con el Consejo de Reparaciones (2008), son “víctimas directas" del conflicto armado quienes han pasado por las siguientes formas de afectación: personas fallecidas y sus familiares, personas desaparecidas y sus familiares, miembros de las Fuerzas del Orden e integrantes de comités de autodefensa y autoridades civiles que hayan resultado heridas o lesionadas, personas objeto de tortura, personas objeto de lesiones graves, personas detenidas de forma ilegal o arbitraria, personas objeto de secuestro, personas objeto de reclutamiento forzoso, personas objeto de violencia sexual y personas que sufrieron formas de violencia sexual distintas de la violación y personas desplazadas. Así, en un primer nivel, el más básico y literal, el desplazamiento y las demás afectaciones listadas pertenecen al mismo universo de daños.

${ }^{15}$ César Tapahuasco, comunicación personal. 


\section{Iván Ramírez Zapata}

Este igualamiento formal no tiene correspondencia en los hechos. No solo porque el Plan Integral de Reparaciones trata de forma diferenciada a distintos tipos de víctima, sino también porque quienes han pasado por estos tipos de afectación tienen distintas percepciones entre sí. Varias de las entrevistas que realicé sugieren que ser desplazado es una suerte de "mal menor" respecto de otras situaciones, llegando incluso a separar el desplazamiento de la noción de víctima. Una entrevistada sostiene:

Desplazados son los que se han escapado de miedo. Yo soy víctima, pero también a la vez soy desplazada porque yo viví allá, yo he estado allá. La diferencia es que ellas son desplazadas y yo soy víctima, es que soy afectada, a mis padres los mataron. Los desplazados no han perdido nada, se habrá dejado sus cosas, se han venido de miedo. Yo, en cambio, lo perdí todo: a mis padres, mi casa la quemaron, todo. Entonces, a mí no, yo soy víctima. ${ }^{16}$

Otra entrevistada sostuvo respecto de una tercera persona que "a ella no le ha pasado nada, solo se vino para acá nada más pero no le mataron a nadie”. ${ }^{17}$ En las visitas de campo realizadas durante el tiempo de la investigación, escuché a dirigentes de distintas organizaciones efectuar la división entre víctima y desplazado respecto de personas distintas. Un ejemplo es el de la Asociación Hijos de Accomarca, conformada por personas naturales del poblado ayacuchano de Accomarca; existe un grupo al cual los dirigentes se refieren como el "grupo víctimas" y un grupo distinto conformado por desplazados; al primer grupo corresponden aquellos incluidos como demandantes en el juicio realizado por el caso de la masacre de Accomarca, ${ }^{18}$ mientras que el segundo lo conforman otros accomarquinos.

Un tercer ejemplo, si bien anecdótico, va en este mismo sentido. Las bases de un concurso de ensayos convocado por el Gobierno regional del departamento de Junín en 2016 contemplaban dos categorías: "libre" y "afectados"; quienes postulasen en la segunda categoría debían constatar su afectación presentando un "certificado de condición de víctima o desplazado” (Yalpana Wasi, 2016, p. 2). Estos casos ejemplifican un sentido común, en el cual la condición de desplazado no implica la condición de víctima.

En estas ideas, resuena la caracterización que hace la CVR al respecto. Para esta, el desplazamiento es una suerte de efecto colateral, una "reacción directa a violaciones específicas de los derechos fundamentales” (CVR, 2003, p. 655). Por ello, la CVR

\footnotetext{
${ }^{16}$ Entrevista con Julia Huamaní (19 de mayo de 2016). Distrito de Ate (Lima).

${ }^{17}$ Entrevista con Antonia Alacote (26 de mayo de 2016). Distrito de Ate (Lima).

${ }^{18}$ Ocurrida el 14 de agosto de 1985 en Accomarca. La acción fue realizada por miembros del Ejército del Perú y dio como resultado 69 víctimas mortales. La sentencia por el caso fue dictada el 1 de septiembre de 2016, que estableció entre 23 y 25 años de cárcel para 10 de los acusados.
} 
entiende que el desplazamiento es un problema vinculado, sobre todo, a las condiciones del entorno en que este ocurre.

Usualmente, las causas del desplazamiento no se pueden concretar en un hecho puntual, sino que son el resultado de numerosos elementos que van colmando de temor a las víctimas y que modifican las condiciones de vida de la población. Generalmente, han concurrido la inexistencia de condiciones de seguridad, la falta de garantías para el ejercicio de los derechos fundamentales, la desarticulación de los sistemas económicos, laborales y fuentes de ingresos y el deterioro de las condiciones de vida (CVR, 2003, t. 6, p. 654).

Si bien este diagnóstico es certero, al ser entendido como un problema que atañe a elementos del sistema social, el desplazamiento es igualado a varios otros problemas de carácter estructural (pobreza, falta de oportunidades, marginación, etc.) y escapan a la lupa de la CVR, cuya preocupación se orientaba más al señalamiento de hechos concretos y de responsabilidades puntuales. Y a pesar de que la CVR observa también que, "pese a su magnitud, este fenómeno estuvo signado por el silencio y su relativa invisibilidad" (CVR, 2003, t. 6, p. 647), el tratamiento que hace del tema es superficial, pues consiste, fundamentalmente, en resumir las principales informaciones recogidas en la bibliografía existente hasta ese momento.

El recuento hecho hasta aquí permite afirmar que hay un espacio de las subjetividades existentes hoy en torno al conflicto donde la idea de víctima y de desplazado no se corresponde, a pesar de la existencia de normativas legales que califican como víctima al individuo desplazado. ${ }^{19}$

\section{Una cuestión conceptual: el sujeto o el contexto}

Las dos consideraciones anteriores se encuentran estrechamente ligadas a una cuestión formal: el concepto de desplazamiento - expuesto al inicio del segundo apartado- no contempla alguna de las acciones concretas que llevan a cabo quienes se desplazan. El primer elemento definitorio del desplazamiento, la migración derivada de una amenaza sobre la seguridad, se refiere a la movilidad física asociada a un peligro real o imaginario. No se señala en qué consiste la amenaza específica, ni qué tipo de agentes la ejecutan, ni bajo qué modalidad o de qué forma ocurre el desplazamiento.

El segundo elemento de la definición, a saber, permanecer dentro del espacio delimitado por fronteras nacionales, es una característica del contexto: demarca - de forma

\footnotetext{
${ }^{19}$ Respecto de Ayacucho, Quispe, Huamaní, Huamán y Choquehuanca (2013, p. 109) señalan que, según los desplazados, las movilizaciones convocadas por organizaciones "de víctimas" no los incluyen (lo que es una clara referencia a la división entre Condecorep y Conavip señalada en el apartado anterior). Según los autores, los desplazados "no han internalizado con claridad su condición de víctimas". Mi argumentación va en un sentido similar, pero evita hacer de la identificación con la idea de "víctima" un asunto de "toma de conciencia". Más bien, considero que esta separación entre "víctima" y "desplazado" tiene que ver con las distintas naturalezas de ambas definiciones y con la historia de discursos y propuestas de atención a las afectaciones del conflicto armado.
} 
bastante laxa- el límite territorial de la migración. Lo único que este elemento nos dice acerca del sujeto desplazado es que no ha salido del país.

En el apartado anterior, he listado las otras formas de afectación derivadas del conflicto reconocidas oficialmente. Una característica de todas ellas es que se definen por algún tipo de acción de la cual alguien es objeto, y no por el contexto en el cual la acción ocurre. Mientras que la definición de desplazamiento nos habla de las condiciones en las que se da la migración, las otras afectaciones se definen por una relación de poder que culmina en un crimen o en un atentado sobre la integridad. De esta manera, las afectaciones distintas del desplazamiento tienen una manifestación material concreta sobre el cuerpo, y son ejecutadas por un perpetrador concreto, que interactúa de forma directa y entra en contacto físico con la víctima. ${ }^{20}$

Si bien todas las formas de afectación se constituyen en categorías definidas en un entorno institucional político y burocrático, solo el desplazamiento no se define por la acción directa y violenta de un agresor sobre el cuerpo de su víctima. Por eso mismo, el concepto normativo de desplazamiento nos dice menos sobre la experiencia del desplazamiento de lo que conceptos normativos de daños como tortura, violación sexual o desaparición - que contemplan acciones concretas- dicen sobre tales experiencias: la tortura o la violación sexual dejan marcas en el cuerpo, la muerte o la desaparición de un pariente es inmediatamente notada porque implica la reducción del grupo familiar. Y dado que en muchos casos una tortura, una violación sexual o una desaparición forzada, por ejemplo, generan un mayor daño individual (porque son ataques directos contra el cuerpo) y colectivo (porque implican la muerte de familiares, amigos y vecinos), es probable que las víctimas identifiquen su situación con estos agravios antes que con el desplazamiento. Siguiendo esa línea de razonamiento, y en concordancia con lo expuesto en el apartado anterior, parece configurarse en un escenario en el cual los desplazados son vistos como personas que han perdido algo, pero no lo suficiente como para merecer la misma atención que aquellos que han sufrido agresiones directas.

\section{¿Quién nombra al desplazado?}

El cálculo del número de desplazados internos a causa del conflicto armado oscila entre 450000 y 600 ooo (Barrantes, 2012). En diversas entrevistas y conversaciones que he

\footnotetext{
${ }^{20}$ Desde el punto de vista de la normativa peruana, esto es así, incluso, para casos de "reclutamiento forzado", afectación definida como un acto "perpetrado por elementos terroristas por el cual se obliga a una persona a participar directa o indirectamente en las actividades subversivas llevadas a cabo contra el Estado" (Consejo de Reparaciones, 2008, p. 14). Urbano y Mayo (2015) han señalado las deficiencias jurídicas presentes en el tratamiento que hace el Plan Integral de Reparaciones respecto del reclutamiento y el uso de niños. Entre otras cosas, sostienen que para el caso del reclutamiento forzado es jurídicamente irrelevante la "voluntad" del menor en contextos de conflicto interno. En un libro reciente, Drumbl (2012) habla del "reclutamiento ilícito" de niños y expone una amplia serie de razones que hacen que los menores de edad participen de grupos armados. Para este autor, el reclutamiento de niños debe ser considerado un delito, incluso, en casos en que estos se enlistan voluntariamente.
} 
sostenido con personas involucradas en el tema, ha quedado claro que 600 ooo es la cifra de referencia más común. Esta estimación, sin embargo, no sería confiable. Isabel Coral, una de las especialistas más importantes sobre desplazamiento interno en el Perú, fue la responsable de proponer esta cifra hacia fines de la década de 1990; su posición actual sobre el tema es muy crítica con la información numérica existente.

Primero, no hay cifras sobre desplazados, ni ahora. Lo que yo hice es un mapa. Ni siquiera es una estadística, ni siquiera es un estudio como para conversar. Por distintas razones yo hice una gira cuatro veces a las zonas [de donde salieron los desplazados], y en cada gira anotaba, verificaba, completaba. Llegaba, el equipo la vaciaba. Teníamos un mapa e íbamos poniendo. Eso lo pusimos en blanco y negro. Y de allí salió con cálculos de cuántas familias tiene la comunidad de no sé qué y no sé cuántos salió un cálculo; 600 ooo, salió así. Yo presento la propuesta de atención, presento este mapa y una estrategia de atención al PAR [Programa de Apoyo al Repoblamiento y Desarrollo de Zonas de Emergencia]. Y así el PAR asumió la cifra y se convirtió en cifra oficial. No movió un dedo para completar eso.21

La dificultad para establecer cifras confiables responde a varias razones. Estas dificultades no son exclusivas del Perú, sino que están presentes en la experiencia internacional. Haciendo un balance sobre diversas situaciones de desplazamiento interno en el mundo, Vincent (2001, p. 5) señala que una de esas dificultades tiene que ver con los "desplazados inadvertidos", es decir, con aquellas personas que no entran en contacto con las instituciones de rescate o ayuda humanitaria - que son las que normalmente obtienen la información sobre el desplazamiento antes que cualquier otro actor-y sobre las cuales, consecuentemente, no se tienen mayores datos, o con aquellas personas que llegan a ciudades con una gran población y se confunden con los pobres urbanos o prefieren simplemente permanecer en el anonimato.

El Perú no es ajeno a esto. Sin ir más lejos, el Registro Nacional para las Personas Desplazadas a cargo del MIMP, que existe desde 2006, tiene algo más de sesenta mil personas registradas. Esta cifra es muy menor al rango aproximado de 450 ooo-600 ooo desplazados, por lo cual es probable que gran parte del universo restante corresponda a "desplazados inadvertidos".

Para un mayor entendimiento de este asunto, una anécdota puede resultar ilustrativa. Al final de una asamblea de Anfasep en la que estuve presente, ${ }^{22}$ una de las dirigentes

${ }^{21}$ Entrevista con Isabel Coral (17 de abril de 2015). Distrito de Cercado de Lima (Lima).

${ }^{22}$ Reunión realizada el 18 de octubre de 2015. 
pidió a sus socias acercarse para llenar la ficha de inscripción como desplazadas en el Registro Único de Víctimas. ${ }^{23}$

SOCIA: ¿Y esta ficha?

DIRIGENTA: Es para llenarla y poder inscribirte como desplazada.

SOCIA: ¿Desplazada? ¿Qué es eso?

DIRIGENTA: Son las personas que se han venido por el terrorismo.

SOCIA: Ya, pero acá qué tengo que llenar.

DIRIGENTA: Lo que dice allí. ¿'Tú no has terminado secundaria? Tú tienes secundaria, pones allí la fecha en que te has venido y dónde vivías antes de venirte.

Si ser desplazado es una cosa, identificarse como tal es otra. Dicho de una manera distinta, no hay vínculo directo entre las dimensiones objetiva y subjetiva del desplazamiento: se puede ser desplazado y no saberlo. Esto no debe sorprender. La categoría “desplazado” nace de instituciones internacionales y es progresivamente exportada hacia diversos países. ${ }^{24} \mathrm{Su}$ origen está vinculado a la labor de organismos que diagnostican, parametrizan y reglamentan el significado de la figura de desplazado interno, y que establecen una serie de protocolos para identificarlos y brindarles atención. De esta manera, solo a través del contacto con el discurso experto de instituciones y grupos que movilizan el tema de desplazamiento interno es que puede empezar un proceso de identificación con esta categoría.

Varios testimonios recogidos dan cuenta de ello. Una entrevistada contó que "cuando nos reunimos vinieron los señores de las reparaciones, los de las oenegés, recién allí me doy cuenta de que éramos desplazados". ${ }^{25}$ Otra persona señala que empieza "a participar de la organización de los desplazados cuando veo que el tío y los otros están llamando a la gente porque decían que iban a salir oportunidades del Ministerio o de las reparaciones también”. ${ }^{26}$ En otros casos, esta identificación ocurre como correlato de las decisiones estatales de política: "Cuando salió la ley del PAR [Programa de Apoyo al Repoblamiento y Desarrollo de Zonas de Emergencia], hay una parte que dice que

\footnotetext{
${ }^{23}$ Listado oficial de personas con derecho a la reparación. Fue creado al inicio de la implementación del Plan Integral de Reparaciones.

${ }^{24}$ Esto es referido en Stepputat y Sørensen (2001). Elmer Galván, antropólogo con años de experiencia en el tema, recuerda: "Los principios rectores son los que homogeneizan el tema de desplazamientos. Antes de 1998, en términos internacionales, cada uno daba el nombre: refugiados internos, desplazados internos, migrantes forzados, o sea, diferentes términos. Pero ante la llegada de Deng, en el ámbito internacional, en los foros comienza a diferenciarse migrante de desplazado. Y ya se empieza a hablar de desplazados internos" (entrevista, 2 de junio de 2015, Cercado de Lima [Lima]). Sintomático de lo que refiere Galván respecto de la variedad de términos con los cuales se hablaba de desplazamiento es el hecho de que dentro de una publicación compilatoria de fines de la década de 1980 Coral (1987) escribe un texto usando la palabra refugiados, mientras que Granda Oré y Gamarra (1987) escriben sobre el mismo tema usando el término desplazados.

${ }^{25}$ Entrevista con Teresa Huaura (16 de mayo de 2016). Distrito de Ate (Lima).

${ }^{26}$ Entrevista con Ramón Cuti (5 de abril de 2015). Distrito de Lurigancho-Chosica (Lima).
} 
una de sus funciones es la de organizar el retorno de los desplazados internos, es allí que yo veo esa palabrita y digo que allí estamos nosotros". ${ }^{27}$ También el contacto con las organizaciones o dirigentes hace que una persona desplazada sepa que su situación se corresponde con la de esta categoría: "Cuando conozco la Asociación de Familias Desplazadas en Lima es que empiezo a saber qué es eso de desplazado”. ${ }^{28}$ En estos casos, además, la llegada de grupos e instituciones con el discurso de desplazamiento interno parece prometer algún tipo de beneficio a mediano plazo, ratificando la idea según la cual el asumirse desplazado ocurre en función de la posibilidad de "beneficiarse de programas destinados a atender sus necesidades" (Distr. GENERAL E/CN.4/1998/53/ Add.2), o de acceder a "fuentes de oportunidades" (Zavala, 2008).

Es posible, por lo demás, que la relevancia que el desplazamiento interno tiene para Colombia, además de la magnitud del fenómeno, tenga justamente que ver con la fuerza de un discurso experto que viene desde el Estado, especialmente en lo jurídico. Así, Guataquí (2010) lista 42 sentencias judiciales desde 1997 y 36 autos de seguimiento a la Sentencia T-025/2004, hito en la historia de pronunciamientos jurídicos del Estado colombiano sobre desplazamiento interno. Aquí, es el discurso experto estatal el que promueve una preocupación sobre el desplazamiento e inicia un proceso de politización de este. Perú, en cambio, carece de pronunciamientos de ese tipo.

A su vez, puede manejarse la hipótesis de que aquellas personas desplazadas que no se encuentran en estado de vulnerabilidad o pobreza sean relativamente indiferentes a lo que esta condición supone. Ilustrativo de ello es lo que un conocido funcionario público involucrado en este tema desde hace décadas señala sobre sí mismo:

A ver, te cuento mi problema. Ya sabes que yo trabajaba en provincia. Yo tengo tres hijos, y vine a Lima por problemas de seguridad, me amenazaron de muerte. [...]. Yo traje y llevé a mis hijos de aquí para allá. Y mis hijos vivieron toda esa incertidumbre y toda esa inseguridad. Ahora una de mis hijas tiene problemas de salud, por esa consecuencia. Entonces, yo digo, ¿es o no es víctima? ¿Yo fui o no fui víctima de desplazamiento? Perdí mi casa, perdí mis cosas. Cuando me vine, todo, de todo me deshice. Y ahora, yo digo, ¿fui o no fui desplazado? Sí. ¿Y soy o no víctima? Hasta ahora. Y mi hija tiene 42 años. En función de la depresión que tiene este familiar mío: los hijos son víctimas de esa secuela. Y no es lo mismo, o no tienen las mismas condiciones de desarrollo que el resto de las personas: son víctimas. ${ }^{29}$

Nótese que, no obstante saberse desplazado, el énfasis de la afectación está puesto en la depresión crónica de su hija y no en él mismo. Pero, además, tampoco está interesado

\footnotetext{
${ }^{27}$ Entrevista con Kevin Anzualdo (2 de febrero de 2016). Distrito de Lurigancho-Chosica (Lima).

${ }^{28}$ Entrevista con Remigio Pablo (31 de enero de 2016). Distrito de Lurigancho-Chosica (Lima).

${ }^{29}$ Entrevista anónima con funcionario (17 de enero de 2015). Cercado de Lima (Lima).
} 
en ser registrado como desplazado, porque no tiene las mismas necesidades que el resto de la población desplazada. Así, si bien es una persona desplazada en sentido estricto, difícilmente podemos asociarla con el arquetipo de víctima propuesto por la CVR. Lo mismo podría decirse de otras personas con un perfil más urbano y no pobre. Esto también es sugerido por un dirigente de desplazados cuando, en un tono que oscila entre la broma y la queja, sostiene sobre los líderes políticos de izquierda que estaban en Ayacucho ciudad (y que formaban parte de la misma agrupación que él a inicios de la década de 1980):

Llego a Huamanga, bien difícil, y voy donde mis amigos revolucionarios y ya no estaban.

Ya se habían venido a Lima, y pucha, qué pena. Estuve como un mes en Huamanga. No

sabía adónde ir. Ellos fueron los primeros en desplazarse..$^{30}$

En suma, la identificación con la figura conceptual de "desplazado" tiene fuentes diversas y surge del contacto con las instituciones que tienen incorporado un discurso experto sobre el tema y que pueden ofrecer algún tipo de beneficio, ya sea material, ya sea moral, a las personas desplazadas. Esta identificación, además, parece tener un sesgo que podríamos denominar "sesgo de clase social”, en cuanto aquellas personas desplazadas que no tienen carencias económicas o que no están en estado de indefensión pueden no reconocerse en esta categoría.

\section{Una migración más}

Otra posible razón de la dificultad para identificarse como desplazado tiene que ver con que la movilidad geográfica es una constante en la historia de la población de origen serrano y rural. En un texto muy poco citado, Stepputat y Sørensen (2001) ${ }^{31}$ sostienen que la manera en que se usa la categoría “desplazado" en el Perú tiene como premisa la idea de que la gente vive en un único lugar de forma estable, ignorando que la historia peruana previa al conflicto armado interno se caracteriza por constantes movimientos migratorios de temporalidad variables y con fines diversos, siendo así que las diferencias entre la migración tradicional y el desplazamiento no son tan marcadas como se acostumbra suponer. Más bien, los autores sostienen que se debe de poner atención central al rol de la movilidad en la historia de la población desplazada, para mostrar que la estancia en zonas de inserción urbanas no son nuevas para quienes huyeron de la violencia, en cuanto la constricción espacial constituye, más bien, una condición desventajosa, ya se trate de desplazados, ya de migrantes económicos.

\footnotetext{
${ }^{30}$ Entrevista con César Tapahuasco (18 de julio de 2012). Cercado de Lima (Lima).

${ }^{31}$ En el momento de publicarse, el trabajo de Diez Hurtado (2003) fue el balance más completo sobre desplazamiento por conflicto armado en el Perú. Al final de este libro, se incluye un anexo donde se ofrece una lista, que pretende ser exhaustiva, de la bibliografía existente sobre el tema para el caso peruano. El artículo referido no aparece en este listado. Tampoco aparece citado en publicaciones posteriores de otros autores (Coral, 2010; Quispe et al., 2013).
} 
Estos antecedentes aparecen también en las conversaciones que he sostenido. Uno de mis entrevistados vivió en Lima algunos años en la década de 1970, para luego volver a Ayacucho y posteriormente vivir la experiencia del desplazamiento. ${ }^{32}$ Otro se encontraba en Lima cuando su comunidad de origen en Ayacucho sufre un atentado y él vuelve para sacar del lugar a su madre. ${ }^{33}$ Una entrevistada vivió toda su vida en la comunidad ayacuchana de Ocros y, recién estando en Lima, en 1981, se enteró de que había nacido en el distrito limeño de La Molina. ${ }^{34}$ Por su parte, un joven historiador refiere que sus padres son ayacuchanos pero migraron a Lima en los primeros años de la guerra, naciendo él en 1983 en el distrito de Miraflores; a los pocos años, los problemas económicos se hicieron agobiantes y él y su familia regresan a Ayacucho. Allí, sin embargo, la vida se militariza y hacia la mitad de la década de 1990 "fuimos a vivir junto con otros desplazados internos al asentamiento humano Quebrada de Manchay, en el sureste de Lima” (Aroni, 2013, p. 21). En la solapa de un libro escrito por un dirigente de desplazados de Junín (Oré, 2001), nos enteramos de que en 1972 ingresó a la Universidad Nacional Mayor de San Marcos, en Lima, a estudiar Ingeniería, carrera que no concluye.

Estamos, pues, ante personas y familias con experiencia migratoria previa al desplazamiento. Y si bien no hay posibilidad de estimar qué tan representativos podrían ser o no los testimonios citados, dan un primer fundamento a la posibilidad de que la experiencia del desplazamiento haya sido procesada, al menos en sus inicios, como una migración más, es decir, como otro momento dentro de una historia de movilización geográfica. De esta manera, es más difícil darle sentido específico al desplazamiento, ${ }^{35}$ en cuanto no se trataría de una experiencia radicalmente nueva, como sí lo serían las formas de violencia extrema y de crisis de vínculos sociales que el conflicto trajo en comunidades rurales (Theidon, 2004). Con esto no sostengo que las dinámicas detrás de los desplazamientos por conflicto armado son las mismas detrás de las migraciones por otras causas. Como señalé antes, aquellos son un efecto de situaciones de violencia generalizada con efectos perjudiciales a largo plazo. Afirmo, más bien, que otra de las razones que evitarían que una persona desplazada se identifique como tal sería el hecho de que asimilaría el desplazamiento a la experiencia migratoria previa antes que a la construcción conceptual jurídica que se usa en las discusiones especializadas.

\section{El desplazamiento y las recomendaciones de reparación}

Entre las recomendaciones que la CVR hizo al Estado peruano, figuró elaborar un programa de reparaciones, que posteriormente se concretó en la ley Plan Integral de

${ }^{32}$ Entrevista con Cirilo Pablo (19 de abril de 2015). Distrito de Lurigancho-Chosica (Lima).

${ }^{33}$ Entrevista con Rafael Huamán (9 de julio de 2016). Distrito de Lurigancho-Chosica (Lima).

${ }^{34}$ Entrevista con Maura Huamaní (19 de mayo de 2016). Distrito de Ate (Lima).

35 De hecho, la primera organización de desplazados, creada en 1984, lleva en su denominación la palabra migrantes: Asociación Comunidades Migrantes Quechuas Jatary Ayllu (Paz Ruiz, 2004, p. 7). 
Reparaciones. En la propuesta, la CVR deja fuera de las reparaciones económicas a las personas cuya principal afectación es el desplazamiento. Sin embargo, las incluye como beneficiarios de lo que denomina Programa de Reparaciones Colectivas. Para la CVR, este programa debe beneficiar a "las comunidades campesinas, comunidades nativas y otros centros poblados afectados" y a "los grupos organizados de desplazados no retornantes" en las zonas de inserción en las que viven (CVR, 2003, t. 9, p. 139).

En la justificación para esta decisión, el Informe final señala que "no se puede compensar la pérdida de un ser querido" y que las muertes de personas cercanas constituyen “daños irreparables" (t. 9, p. 135). La reparación económica buscaría resarcir, en parte, esta situación. En cambio, respecto de las condiciones en que vivía una persona antes de desplazarse, la CVR sostiene que estamos ante una realidad reestablecible. En efecto, la justificación del Programa de Reparaciones Colectivas afirma que sí se puede lograr "el restablecimiento de las condiciones de vida de los peruanos después de la violencia” (t. 9, p. 138). Dicho de forma esquemática, para los “daños irreparables” se proponen reparaciones económicas y para las "condiciones reestablecibles" se proponen reparaciones colectivas. Esta distinción ha sido adoptada por el Plan Integral de Reparaciones que, en efecto, no incluye a los desplazados como beneficiarios de reparaciones económicas, pero contempla un programa de reparaciones colectivas para esta población (Mimdes, 2010). ${ }^{36}$

Si bien es innegable que hay buenas razones para considerar la pérdida de vidas humanas como una tragedia mayor, puede cuestionarse que esta justificación sea suficiente para negar la reparación económica por desplazamiento. En primer lugar, porque es imposible no preguntarse si acaso no hay algo irreparable en el desplazamiento y si al dejar de tomar esto en cuenta no se está minimizando arbitrariamente la afectación del desplazamiento y sus consecuencias. No es mi objetivo ahondar en ello; baste con plantear la pregunta y sugerirla como un posible punto de partida para futuras reflexiones. En segundo lugar, porque hay algunas experiencias internacionales donde los desplazados sí están presentes en los esquemas de reparación económica. En Turquía, se emitió en 2004 una ley de compensación que disponía el pago de dinero a personas desplazadas a causa de sus propiedades perdidas por el conflicto entre las Fuerzas Armadas turcas y los grupos kurdos insurgentes (1978-presente) (Kurban, 2012). Colombia

\footnotetext{
36 Una reparación colectiva consiste en concretar un proyecto por un valor máximo de hasta 100000 soles, cuyos beneficiarios son de dos tipos: 1) comunidades andinas y amazónicas que sufrieron los impactos de la violencia y 2) grupos de desplazados no retornantes, es decir, conformados por personas desplazadas que no hayan vuelto al lugar en el que residían cuando el conflicto estalló. Las reparaciones colectivas empezaron a implementarse en 2007, siendo dirigidas solo al primer grupo de beneficiarios, en tanto que recién en 2013 se aprueban los lineamientos para entregar reparaciones colectivas a los grupos de desplazados no retornantes. El desplazamiento, pues, fue también relegado en lo referente a las reparaciones colectivas dentro de la implementación del Plan Integral de Reparaciones.
} 
contempla reparaciones económicas a núcleos familiares de desplazados, cuyo monto se ha establecido según una sentencia judicial de 2013 (Unidad para las Víctimas, s. f.).

Un comentario adicional. El acceso a las reparaciones colectivas requiere estar involucrado en un colectivo de desplazados, lo cual supone también la obligatoriedad de llevar a cabo un trabajo de acción colectiva en función de acceder a este programa de reparación. Esto nos pone en una situación paradójica: a la par que la CVR trata el tema del desplazamiento de forma poco profunda, los desplazados constituyen el grupo al cual se les exige los mayores requisitos para acceder a reparaciones. No solo tiene cada desplazado que hacer las gestiones propias del acceso a los beneficios individuales, contemplados para todos los afectados, sino que además tienen que hacer una serie de gestiones grupales propias de los requisitos establecidos para reparar colectividades y así deben afrontar los avatares y costos que implican las experiencias de acción colectiva.

\section{Conclusiones}

El desplazamiento interno fue el fenómeno de mayor magnitud numérica durante el conflicto interno peruano. Sin embargo, este tema no figura en los principales debates académicos y son pocas veces mencionados en las discusiones sobre las deudas del Estado respecto del conflicto. A partir del contraste entre la conceptualización normativa de desplazamiento y los sentidos y las narrativas que las personas desplazadas dan a esta experiencia, postulo que el relegamiento de la afectación del desplazamiento en la agenda posconflicto peruano se sostiene en varios factores. El primero es que la identidad de desplazado es una identidad secundaria en un contexto en el que hay otras formas de acceder a los derechos de justicia, verdad y reparación. Esto, además, como correlato de un discurso - presente en la CVR - en el cual el desplazamiento no traduce en sí mismo la violación de un derecho fundamental - al menos no en la misma medida que crímenes como violación sexual, tortura o desaparición-y de un imaginario según el cual ser "desplazado" y ser "víctima" no es lo mismo.

Entender el desplazamiento como una secuela más que como una violación a un derecho no es, sin embargo, caprichoso. En efecto, el desplazamiento tiene menos consecuencias para la identidad del afectado, y no supone necesariamente haber sido sometido a un atentado contra la integridad personal. Y si bien el conjunto de categorías presentes en el campo de la atención y reparación (“desaparecido", "torturado", "desplazado", etc.) tiene un origen en instituciones humanitarias y ámbitos jurídicos, solo el desplazamiento no aparece definido por una agresión contra el cuerpo o la libertad de movimiento, lo cual abona a la dificultad de identificarse como tal. En ese sentido, es razonable pensar que el número de "desplazados inadvertidos" disminuya cuando los discursos expertos sobre desplazamiento puedan intensificarse o extenderse, pues todo hace indicar que ello es necesario para que las personas objetivamente desplazadas 
se identifiquen como tales. Por cierto, los expertos internacionales reconocen también que este es un problema que no atañe a país alguno en específico, sino que históricamente ha sido difícil hacer dialogar los discursos académicos y políticos sobre desplazamiento con las temáticas de derechos humanos (Duthie, 2011).

Otro factor que dificulta la identificación subjetiva con el desplazamiento es el hecho de que es un fenómeno que tiene continuidad respecto de etapas previas de migración. Por mucho tiempo se sostuvo que el desplazamiento era un tipo radicalmente nuevo de migración (Coral, 1994). Sin embargo, esto pierde de vista el hecho de que muchos desplazados tenían experiencia previa en ciudades. Si combinamos esta idea con aquella otra que se desprende de algunas entrevistas, a saber, que hay un "sesgo de clase social" en la identificación con el desplazamiento, terminamos entrando en un viejo problema que no siempre está presente en la agenda posconflicto: la pobreza. Varias publicaciones (Lozano, 2014; Misión ICVA, 1997) han resaltado esta característica como un problema fundamental del desplazamiento. Así, si algún vínculo puede existir entre la preocupación por la pobreza y la preocupación por las deudas sobre derechos humanos, el tema del desplazamiento bien puede ser el lugar adecuado para articularlo.

El movimiento de derechos humanos ha hecho de las reparaciones uno de sus principales temas de preocupación (Bebbington, Scurrah y Bielich, 2011). Como he mostrado, el desplazamiento es presentado por la CVR como una afectación "reestablecible", es decir, cuya gravedad es menor respecto de otras, consideradas "irreparables". Así, es entendible que el trabajo de las organizaciones de derechos humanos no atienda el desplazamiento de la misma manera que atiende otras afectaciones. Y si bien los desplazados comparten las mismas características con el grueso de víctimas de perfil rural y quechuahablante, su acceso a reparaciones colectivas supone requerimientos mucho mayores, pues, al tratarse de proyectos que involucran infraestructura, estas pasan por una mayor cantidad de instancias burocráticas (registros públicos, proyectistas, autoridades locales, etc.), lo que requeriría de un mecanismo especial permanente de asesoría legal y acompañamiento que, hasta donde se sabe, no existe.

Paradójicamente, no obstante encontrarse en una situación que combina retos relativos al combate a la pobreza y a la reparación, los desplazados no son figuras centrales en el tratamiento de dichos temas. Esto conduce a preguntar qué pueden tener que ver los enfoques de reducción de la pobreza con otro de promoción de derechos. Se ha sostenido que el Estado peruano impuso al Plan Integral de Reparaciones las mismas metodologías de identificación de víctimas que usa para identificar "bolsones" de pobreza, con lo cual creó “jerarquías de merecimiento" que "reflejan las características individuales [género, edad, afectación sufrida] de las víctimas antes que la naturaleza de la violencia que experimentaron (Ulfe, 2015, p. 19). Esta forma de administrar las reparaciones sería consecuencia de "la narrativa neoliberal que se ha guiado de una aproximación 
estadística a la reducción de la pobreza". ${ }^{37}$ Este argumento resulta arbitrario en cuanto no explica cuál es el inconveniente de medir estadísticamente la reducción de la pobreza ni por qué ello sería privativo del neoliberalismo. Pero más importante es observar que si siguiésemos la propuesta de esta autora tendría que dejarse de lado un enfoque de combate a la pobreza en la atención de aquella población desplazada que no cuenta con alguna afectación asociada a victimización mortal, lo cual perjudicaría sus perspectivas de reconstrucción.

Una observación similar puede hacerse respecto del espectro de demandas de la agenda posconflicto. ¿Qué respuesta dar para atender las carencias y desventajas sufridas por quienes no son considerados "víctimas" pero que, no obstante, pueden legítimamente reclamarse afectados por el conflicto armado? Algunos pocos trabajos (Delacroix, 2014; Portugal Teillier, 2015, pp. 186-188; Reátegui, 2010, pp. 69-70) han venido observando el vínculo entre las demandas de derechos y desarrollo presentes en algunas comunidades y grupos de víctimas. Bebbington, Scurrah y Bielich (2011, pp. 271-272) lo expresan así:

Las poblaciones afectadas no desean reparaciones o desarrollo, sino que desean ambos. Y se considera que ambas deben ser medidas destinadas a resarcir daños ocurridos durante la violencia. Hay aquí, entonces, cierta disonancia con la posición del movimiento de derechos humanos (y compartida por la Defensoría del Pueblo) de que las reparaciones no deben apuntar al desarrollo.

Hace un lustro, una organización nacional de desplazados resumía en una oración las expectativas y los anhelos de los desplazados en ciudades: "vivienda, trabajo, salud y educación" (Condecorep, 2011, p. 34). Es decir, aquellos elementos básicos necesarios para hacer digna una vida, cuya concreción dotaría de efectividad práctica las promesas de inclusión y ciudadanía. Así, el desplazamiento interno es uno de los temas que reclaman articulación entre los enfoques de derechos humanos, reconstrucción y desarrollo (o lucha contra la pobreza). Si bien es necesario continuar persiguiendo la dignificación de los familiares de las personas desaparecidas e intensificar la lucha por lograr justicia, parece igual de importante abrir el espectro de la justicia transicional y tender puentes para ir incluyendo en su centro las afectaciones que, como es el caso del desplazamiento interno, han recibido históricamente menos atención respecto de otras.

\section{Referencias}

Akresh, R. y Walque, D. de (2008). Armed conflict and schooling: Evidence from the 1994 Rwandan genocide. Washington, D. C.: World Bank Publications.

${ }^{37}$ Las traducciones son mías. 
Aroni Sulca, R. (2013). Sentimiento de pumpín: música, migración y memoria en Lima, Perú (Tesis de maestría, Universidad Nacional Autónoma de México, México).

Anfasep (Asociación Nacional de Familiares de Secuestrados, Detenidos y Desaparecidos del Perú) (2007). ¿Hasta cuándo tu silencio? Testimonios de dolor y coraje. Huamanga: Anfasep.

Aprodeh (Asociación Pro Derechos Humanos) (2000). Los desplazados. 6oo,ooo ciudadanos peruanos sin derechos. Lima: Aprodeh.

Barrantes Segura, R. (2012). Reparations and displacement in Peru. Nueva York: ICTJ/ Brookings.

Bebbington, A., Scurrah, M. y Bielich, C. (2011). Los movimientos sociales y la política de la pobreza en el Perú. Lima: Instituto de Estudios Peruanos.

Belaúnde, C. de (2012). La Comisión de la Verdad, la enseñanza de la historia y los textos escolares. Revista Argumentos, 2. Recuperado de http://revistaargumentos.iep.org.pe/articulos/la-comision-de-la-verdad-la-ensenanza -de-la-historia-y-los-textos-escolares/

Bundervoet, T., Verwimp, P. y Akresh, R. (2009). Health and civil war in rural Burundi. Journal of Human Resources, 44(2), 536-563.

Burt, J. M. y Rodríguez, M. (2014). The paradoxes of accountability: Transitional justice in Peru. En S. J. Stern y S. Straus (eds.), The human rights paradox: Universality and its discontents (pp. 148-174). Madison: University of Wisconsin Press.

Colectivo Desvela (2015). Chinkaqkuna: los que se perdieron. Lima: Colectivo Desvela.

Condecorep (Coordinadora Nacional de Desplazados y Comunidades en Reconstrucción del Perú) (2004). Espejo de la verdad: memorias para no olvidar, lecciones para la historia. Lima: Condecorep.

Condecorep (Coordinadora Nacional de Desplazados y Comunidades en Reconstrucción del Perú) (2011). Agenda nacional de las y los desplazados: propuesta de la Condecorep para la reparación integral a las y los desplazados por la violencia política en el Perú. Lima: Condecorep.

Consejo de Reparaciones (2008). Reglamento de inscripción en el Registro Único de Víctimas de la Violencia a cargo del Consejo de Reparaciones. Lima: Consejo de Reparaciones.

Coral, I. (1987). Refugiados ayacuchanos en Lima: los niños de la guerra. Ayacucho: Instituto de Estudios Regionales José María Arguedas. 
Coral, I. (1994). Desplazamiento por violencia política en el Perú. Lima: Instituto de Estudios Peruanos.

Coral, I. (2002). Comunidades campesinas y desplazamiento forzado. Ponencia presentada en la Audiencia pública temática de la Comisión de la Verdad y Reconciliación: Comunidades campesinas y desplazamiento forzado, Lima.

Coral, I. (2010). Políticas, estrategias y mecanismos de reparación para la población afectada por desplazamiento forzado en el Perú. En C. Díaz Gómez y A. Zamora (eds.). Reparar el destierro: lecciones para la reparación a las víctimas del desplazamiento forzado en Colombia desde la experiencia comparada (pp. 156-206). Bogotá: Centro Internacional para la Justicia Transicional.

Coronel, J. (1999). Balance del proceso de desplazamiento por violencia en el Perú, 1980-1997. En V. Ágreda, A. Diez y M. Glave (eds.), Perú: el problema agrario en debate (pp. 587-624). Lima: Servicio Permanente de Investigación Agraria.

CVR (Comisión de la Verdad y Reconciliación) (2003). Informe final (t. 2, 6, 8 y 9). Lima: CVR.

Defensoría del Pueblo (2006). El difícil camino de la reconciliación: justicia y reparación para las víctimas de la violencia. Lima: Defensoría del Pueblo.

Defensoría del Pueblo (2008). A cinco años de los procesos de reparación y justicia en el Perú: balance y desafíos de una tarea pendiente. Lima: Defensoría del Pueblo.

Defensoría del Pueblo (2013). A diez años de verdad, justicia y reparación: avances, retrocesos y desafíos de un proceso inconcluso. Lima: Defensoría del Pueblo.

Degregori, C. I. (2011). Introducción. En Qué difícil es ser Dios: el Partido Comunista del Perú, Sendero Luminoso y el conflicto armado interno en el Perú: 1980-1999 (pp. 17-81). Lima: Instituto de Estudios Peruanos.

Degregori, C. I. (2015). Sobre la Comisión de la Verdad y Reconciliación en el Perú. En C. I. Degregori, T. Portugal Teillier, G. Salazar Borja y R. Aroni Sulca, No hay mañana sin ayer: batallas por la memoria y consolidación democrática en el Perú (pp. 27-68). Lima: Instituto de Estudios Peruanos.

Degregori, C. I., Portugal Teillier, T., Salazar Borja, G. y Aroni Sulca, R. (2015). No hay mañana sin ayer: batallas por la memoria y consolidación democrática en el Perú. Lima: Instituto de Estudios Peruanos.

Delacroix, D. (2014). "Somos peruanos y limpios": discursos y prácticas en torno al monumento "El Ojo que Llora", de Llinque, Apurímac. Bulletin de l'Institut français d'études andines, 43(2), 227-244. 
Del Pino, P. (2003). Uchuraccay: memoria y representación de la violencia política en los Andes. En C. I. Degregori (ed.), Jamás tan cerca arremetió lo lejos: memoria y violencia política en el Perú (pp. 49-94). Lima: Instituto de Estudios Peruanos.

Distr. GENERALE/CN.4/1998/53/Add.2. Intensificación de la promoción y el fomento de los derechos humanos y las libertades fundamentales, en particular la cuestión del programa y los métodos de trabajo de la Comisión (11 de febrero de 1998). Recuperado de http://www.hchr.org.co/documentoseinformes/documentos/ html/informes/onu/resdi/E-CN-4-1998-53-ADD-2.html

Diez Hurtado, A. (2003). Los desplazados en el Perú. Lima: Comité Internacional de la Cruz Roja.

Drinot, P. (2009). For whom the eye cries: Memory, monumentality, and the ontologies of violence in Peru. Journal of Latin American Cultural Studies, 18(1), 15-32.

Drumbl, M. A. (2012). Reimagining child soldiers in international law and policy. Oxford: Oxford University Press.

Duthie, R. (2011). Transitional justice and displacement. International Journal of Transitional Justice, 5(2), 241-261.

Francke, P., Castro, A., Francke, M. y Espino, J. (2001). La experiencia del Programa de Apoyo al Repoblamiento y Desarrollo de Zonas de Emergencia: lecciones para redefinir la estrategia de intervención estatal en poblaciones afectadas por la violencia política. Allpanchis, 31(58), 33-111.

Gibaja Vargas-Prada, P. S. (1994). Aproximaciones a la situación de los desplazados en el Perú. Lima: Gibaja Vargas-Prada.

Granda Oré, J. y Gamarra, J. (1987). ¿Hasta cuándo pues señor así estaremos en esta desolación? Reflexiones sobre la conciencia campesina en poblaciones desplazadas. En Los niños de la guerra (pp. 67-77). Huamanga: Instituto de Estudios Regionales José María Arguedas.

Grimard, F. y Laszlo, S. (2014). Long-term effects of civil conflict on women's health outcomes in Peru. World Development, 54, 139-155.

Guataquí, J. C. (2010). ¿Cómo medir la magnitud del desplazamiento? La dimensión del desplazamiento en Colombia: la problemática del sistema de registro y caracterización de la población desplazada. En C. Rodríguez Garavito (coord.), Más allá del desplazamiento: políticas, derechos y superación del desplazamiento forzado en Colombia (pp. 38-71). Bogotá: Universidad de los Andes.

IASC (Inter-Agency Standing Committee) (2010). IASC Framework on durable solutions for internally displaced persons. Washington: IASC/University of Bern. 
IDL (Instituto de Defensa Legal) (1997). Consulta sobre desplazamiento y refugio en la región andina. Lima: IDL.

Kirk, R. (1991). La década de chaqwa: los desplazados internos en el Perú. Coordinadora Nacional de Derechos Humanos.

Kurban, D. (2012). Reparations and displacement in Turkey. Nueva York: ICTJ/ Brookings.

Leckie, S. (2007). Housing, land, and property restitution rights of refugees and displaced persons: Laws, cases and materials. Nueva York: Cambridge University Press.

León, G. (2012). Civil conflict and human capital accumulation the long-term effects of political violence in Perú. Journal of Human Resources, 47(4), 991-1022.

Lerner Febres, S. (2012). La agenda de la verdad y la justicia a nueve años de la presentación del informe final de la CVR del Perú. Recuperado de http://idehpucp. pucp.edu.pe/images/publicaciones/ooomemoriao8_articuloo6.pdf

Lozano Martínez, F. J. (2014). Desplazados por violencia en asentamientos humanos de Huanta y Lima, Perú. Guadalajara: Universidad de Guadalajara.

Mendoza Mesías, L. C. (2012). Los nuevos horizontes de las familias desplazadas de Ayacucho y Huancavelica, proceso de inserción en zonas urbanas: el caso de Huancayo (Tesis de maestría, Pontificia Universidad Católica del Perú, Lima).

Milton, C. E. (2015). Desfigurando la memoria: (des)atando los nudos de la memoria peruana. Anthropologica, 33(34), 11-33.

Mimdes (Ministerio de la Mujer y Desarrollo Social) (2010). Compendio de normas y documentos sobre desplazamientos internos. Lima: Mimdes.

MIMP (Ministerio de la Mujer y Poblaciones Vulnerables) (2012). Población desplazada en cifras estadísticas. Lima: MIMP.

Misión ICVA (1997). Informe dela Misión ICVA al Perú. En Consulta sobre desplazamiento y refugio en la región andina (pp. 221-242). Lima: Instituto de Defensa Legal.

Moya Medina, J. (2010). Desplazamiento y cambios en salud. Ayacucho, Perú: 19802004. Lima: Organización Panamericana de la Salud.

Muñoz, H. (1999). Derechos humanos y construcción de referentes sociales. En S. J. Stern (ed.), Los senderos insólitos del Perú: guerra y sociedad, 1980-1995 (pp. 435-454). Lima: Instituto de Estudios Peruanos.

Oficina de Coordinación de Asuntos Humanitarios de las Naciones Unidas (2010). Principios rectores de los desplazamientos internos. En Compendio de normas 
y documentos sobre desplazamientos internos (pp. 9-21). Lima: Ministerio de la Mujer y Desarrollo Social.

Oré Cárdenas, E. (2001). Ayahuanco: bajo la sombra de Sendero: un testimonio de parte sobre la violencia. Lima: Instituto de Defensa Legal.

Paz Ruiz, R. (2004). Mapeo de las organizaciones de afectados por la violencia política en el Perú. Lima: Oxfam.

Portugal Teillier, T. (2015). Batallas por el reconocimiento: lugares de memoria en el Perú. En C. I. Degregori, T. Portugal Teillier, G. Salazar Borja y R. Aroni Sulca, No hay mañana sin ayer: batallas por la memoria y consolidación democrática en el Perú (pp. 69-235). Lima: Instituto de Estudios Peruanos.

Quispe Córdova, M. N., Humaní Palomino, G., Huamán Ramos, C. y Choquecahua I., L. (2013). Los desplazados en los distritos urbanos de Huamanga: un diagnóstico. Huamanga: Centro Loyola.

Ragas, J. (2013). Los historiadores y el Informe final de la Comisión de la Verdad y Reconciliación (Perú, 2003-2013). Revista Argumentos, 4. Recuperado de http:// revistaargumentos.iep.org.pe/articulos/los-historiadores-y-el-informe-final-dela-comision-de-la-verdad-y-reconciliacion-peru-2003-2013/

Reátegui, F. (2010). Los sitios de la memoria: procesos sociales de la conmemoración en el Perú. Lima: Pontificia Universidad Católica del Perú.

Rénique, J. L. (2015). Incendiar la pradera: un ensayo sobre la revolución en el Perú. Lima: La Siniestra Ensayos.

Rodríguez Garavito, C. y Rodríguez Franco, D. (2010). El contexto: el desplazamiento forzado y la intervención de la Corte Constitucional (1995-2009). En C. Rodríguez Garavito (coord.). Más allá del desplazamiento: políticas, derechos y superación del desplazamiento forzado en Colombia (pp. 14-35). Bogotá: Universidad de los Andes.

Salazar Borja, G. (2015). Sin debates no hay campo: un acercamiento a los estudios sobre memorias de violencia política en el Perú. En C. I. Degregori, T. Portugal Teillier, G. Salazar Borja y R. Aroni Sulca, No hay mañana sin ayer: batallas por la memoria y consolidación democrática en el Perú (pp. 237-301). Lima: Instituto de Estudios Peruanos.

Stepputat, F. y Sørensen, N. N. (2001). The rise and fall of 'internally displaced people'in the central Peruvian Andes. Development and Change, 32(4), 769-791.

Tamayo, A. M. (2003). Anfasep y la lucha por la memoria de sus desaparecidos (19832000). En C. I. Degregori (ed.), Jamás tan cerca arremetió lo lejos: memoria y violencia política en el Perú (pp. 95-134). Lima: Instituto de Estudios Peruanos. 
Theidon, K. (2004). Entre prójimos: el conflicto armado interno y la política de la reconciliación en el Perú. Lima: Instituto de Estudios Peruanos.

Tinoco, A. y Cáceres, E. (1999). Violencia, exclusión y desarrollo: la experiencia de las comunidades campesinas de Julcamarca. Lima: Asociación Pro-Derechos Humanos.

Uccelli, F., Agüero, J. C., Pease, M. A., Portugal Teillier, T. y Del Pino, P. (2013). Secreto a voces: memoria y educación en colegios públicos de Lima y Ayacucho. Lima: Instituto de Estudios Peruanos.

Ulfe, M. E. (2015). Neoliberal reforms, reparations, and transitional justice measures in torn-apart. CRPD Working Paper, 41.

Unidad para las Víctimas (s. f.). Indemnización. Recuperado de http://www.unidadvictimas.gov.co/es/indemnizaci \% 3 \%B3n/8920

UNHCR (United Nations High Commissioner for Refugees) (2004). Poverty reduction strategy papers: A displacement perspective. UNHCR.

United Nations, Economic and Social Council. E /CN.3/2016/14. Report of Statistics Norway, the Turkish Statistical Institute, Eurostat and the Office of the United Nations High Commissioner for Refugees on progress in the work on statistics on refugees and internally displaced persons (18 diciembre 2015).

Urbano, Y. y J. Mayo (2015). El reclutamiento y utilización de niños en el Plan Integral de Reparaciones del Perú. En II Concurso de Investigación en Derechos Humanos y Derecho Internacional Humanitario: Compilación de textos ganadores (pp. 208-295). Lima: Instituto de Democracia y Derechos Humanos.

Vincent, M. (2001). Introduction and background. En M. Vincent y B. Refslund Sorensen (eds.), Caught between borders: Response strategies of the internally displaced (pp. 1-14). Londres: Norwegian Refugee Council.

Yalpana Wasi (2016). Concurso de ensayos: Región Junín, Promoviendo Cultura de Paz. Junín: Yalpana Wasi.

Youngers, C. (2003). Violencia política y sociedad civil en el Perú: historia de la Coordinadora Nacional de Derechos Humanos. Lima: Instituto de Estudios Peruanos.

Zavala Respaldiza, Z. (2008). La construcción del dirigente: una aproximación a las organizaciones de desplazados por la violencia política y sus redes de relaciones (Tesis de grado, Pontificia Universidad Católica del Perú, Lima). 